\title{
In vitro evaluation of antibacterial activity in ethanolic extract of whole plant Sphaeranthus indicus Linn.
}

\author{
Preeja K. Sundaresan ${ }^{1 *}$, Kala P. Kesavan ${ }^{2}$
}

${ }^{1}$ Department of Pharmacology, Government Medical college, Thiruvananthapuram, Kerala, India

${ }^{2}$ Department of Pharmacology, Government Medical college, Aleppey, Kerala, India

Received: 14 September 2020

Accepted: 29 September 2020

\section{*Correspondence:}

Dr. Preeja K. Sundaresan,

Email: drpreeja79@rediffmail.com

Copyright: () the author(s), publisher and licensee Medip Academy. This is an open-access article distributed under the terms of the Creative Commons Attribution Non-Commercial License, which permits unrestricted non-commercial use, distribution, and reproduction in any medium, provided the original work is properly cited.

\begin{abstract}
Background: Sphaeranthus indicus Linn is a widely used medicinal plant in Indian traditional system of medicine against human pathogens. Alarming bacterial resistance is urging scientist to search for newer anti-microbial substances from the medicinal plants. The objective of the study was to evaluate the antibacterial activity of ethanolic extract of the whole plant Sphaeranthus indicus Linn (Asteraceae).

Methods: The antibacterial activity of ethanolic extract of whole plant of Sphaeranthus indicus Linn was done against Escherichia coli, Pseudomonas aeruginosa, Proteus mirabilis and Staphylococcus aureus in Mueller Hinton Agar (MHA) and compared with ciprofloxacin as standard by disc diffusion method.

Results: The study revealed that there was no zone of inhibition in doses of $100 \mathrm{mcg}, 200 \mathrm{mcg}$ and $300 \mathrm{mcg}$ of ethanolic whole plant extract of Sphaeranthus indicus in MHA plates compared with ciprofloxacin $30 \mathrm{mcg}$.

Conclusions: Ethanolic extract of Sphaeranthus indicus does not have antibacterial activity. Further studies are needed in different extracts and parts of the plant. Simultaneous studies can be done in different places to evaluate environmental factors and regional variations.
\end{abstract}

Keywords: Sphaeranthus indicus, Escherichia coli, Pseudomonas aeruginosa, Proteus mirabilis, Staphylococcus aureus, In vitro, Disc diffusion

\section{INTRODUCTION}

Herbal medicines are naturally occurring, plant-derived products having minimal or no industrial processing which are available as local and regional treatment modalities. Different societies across the world have shown great interest in curing illnesses using plants/plantbased drugs. ${ }^{1}$ Sphaeranthus indicus L . is a medicinal plant found in India and Malaysia belonging to Asteraceae family which is has 1,100 genera worldwide and 19,000 species. It is a herb called as mundi, nearly $30 \mathrm{~cm}$ or 1 foot high with spreading branches, seen all over India, especially in hills, as weed in the paddy fields. All parts of the plant are used for medicinal purpose. The roots and seeds are used by traditional practitioners as an anthelminthic in doses of 40 grams daily in the form of powder. Powder of the roots and seeds is given along with honey, in cough. The root-bark grounded and mixed with whey is very useful in bleeding piles, and is also used as paste topically. The oil extracted from the roots by steam distillation, and boiled in sesame oil, is recommended by traditional practitioners as a valuable aphrodisiac. Other uses are in glandular swellings in the neck and also in jaundice. This drug is also useful in urethral discharges. $S$. indicus has long been used in the treatment of skin infection, bronchitis, jaundice and nervous depression. ${ }^{2}$ The herb is also reported to be useful as a tonic to treat indigestion, asthma and dysentery. ${ }^{3}$

The whole plant and its anatomical parts have been reported with different types of secondary metabolites 
which include eudesmanolides, sesquiterpenoids, sesquiterpene lactones, sesquiterpene acids, flavone glycosides, flavonoid C-glycosides, isoflavone glycoside, sterols, sterol glycoside, alkaloid, peptide alkaloids, amino acids and sugars. ${ }^{4} \mathrm{~A}$ bicyclic sesquiterpene lactone isolated from the petroleum ether extract of the aerial part of the $S$. indicus was reported to have antimicrobial activity against Staphylococcus aureus, Escherichia coli, Fusarium sp, and other microorganisms..$^{5}$ Antimicrobial activity of alkaloidal and nonalkaloidal fractions of alcoholic extract of flowers has also been reported. ${ }^{6}$ The objective of this study was to evaluate the antibacterial activity of ethanolic extract of whole plant of $S$. indicus in three concentrations $(100 \mathrm{mcg}, 200 \mathrm{mcg}, 300 \mathrm{mcg}$ per disc) in vitro by using disc diffusion method. The antibacterial activity of whole plant ethanolic extract of $S$. indicus was compared with ciprofloxacin as the standard.

\section{METHODS}

\section{Plant collection}

The whole plant $S$. indicus was obtained locally and was authenticated by the Pharmacognosy unit, Ayurveda Research Institute, Poojappura, Thiruvananthapuram, Kerala, India. The procured plant material was disease free and also not contaminated with other plants. Distilled water was used to clean the whole plant material and surface sterilization was done with $70 \%$ ethanol. They were cut into small pieces and shade drying was done. Finally, they were completely made into powder form.

\section{Preparation of ethanolic extract}

It was pre extracted on petroleum ether in order to defatten the material. Soxhlet extraction was done with $90 \%$ ethanol. After that the extract was distilled and then dried in a previously weighed beaker in order to get rid of solvent. Whatman no.1 filter paper was used for filtration. They were stored at $4^{\circ} \mathrm{C}$ for further use. Three increasing concentrations of $100 \mathrm{mcg} / \mathrm{ml}, 200 \mathrm{mcg} / \mathrm{ml}$, $300 \mathrm{mcg} / \mathrm{ml}$ were prepared in dimethylformamide purchased from chemical store which was manufactured by Qualigens Fine Chemicals, division of Glaxo smith Kline Pharmaceuticals Limited, Mumbai

\section{Antibacterial strains}

Antibacterial strains used were Pseudomonas aeruginosa, Escherichia coli, Proteus mirabilis and Staphylococcus aureus obtained from the Microbiology department in Government Medical College, Thiruvananthapuram.

\section{Antibacterial activity}

Antibacterial activity was done using culture media, plates, filter papers, standard drug and bacterial strains obtained from Department of Microbiology, Medical College, Thiruvananthapuram. Pseudomonas aeruginosa,
Escherichia coli, Proteus mirabilis and Staphylococcus aureus were sub cultured on peptone water at $37{ }^{\circ} \mathrm{C}$ for 24 hours. Ethanolic extract of whole plant of $S$. indicus in three concentrations $(100 \mathrm{mcg}, 200 \mathrm{mcg}, 300 \mathrm{mcg}$ per disc) were prepared in sterile dimethyl formamide (DMF). Control tests was done using equivalent amounts of the solvent (DMF). Ciprofloxacin, a quinolone in a dose of $30 \mathrm{mcg}$ was used as the standard. The discs $(6$ $\mathrm{mm}$ diameter was cut from whatman No:1 filter paper) were autoclaved first and then soaked with the three increasing doses of the extract and dried. Next they were applied to the surface of Mueller Hinton Agar (MHA) plates seeded with bacteria and then incubated at $37{ }^{\circ} \mathrm{C}$ for 24 hours. The plates were observed for the presence or absence of zone of inhibition at the end of 24 hours and it was also repeated for 5 days. The test was done in triplicate.

\section{RESULTS}

As shown in (Figure 1 to 4 ) and as summarized in (Table 1 ), in this in vitro study, it was observed that the ethanolic whole plant extract of Sphaeranthus Linn didn't exhibit antibacterial activity against Escherichia coli, Pseudomonas aeruginosa, Klebsiella and Staphylococcus aureus. The effect of $S$. indicus on the growth of bacteria was compared with ciprofloxacin as standard drug.

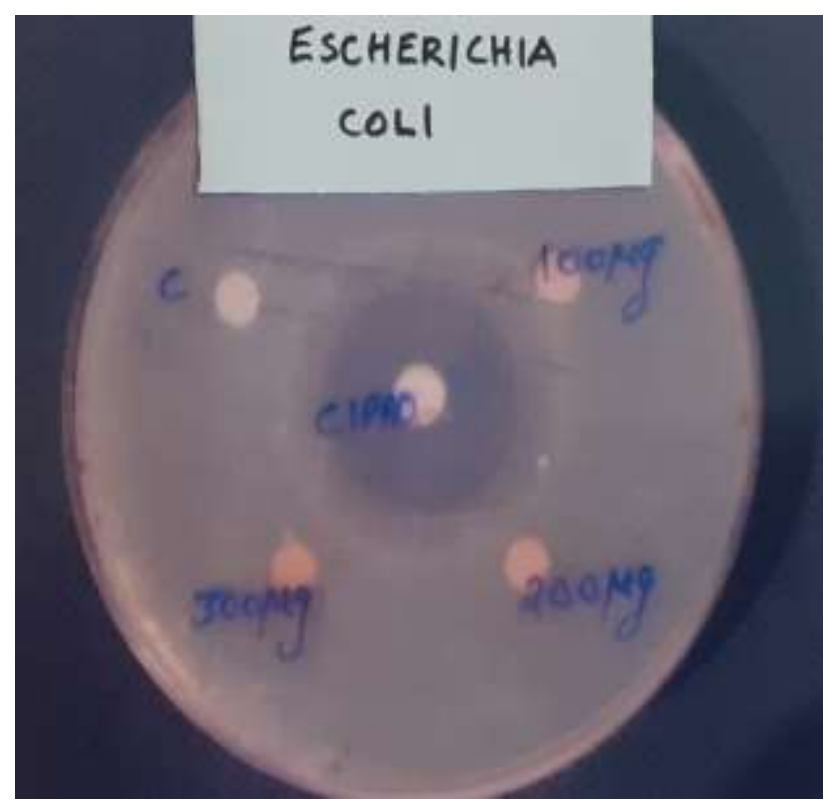

Figure 1: Effect of ethanolic extract of whole extract of S. indicus Linn, control and ciprofloxacin on growth of E coli.

In this disc diffusion method of study with ciprofloxacin as standard drug, Escherichia coli, Pseudomonas aeruginosa, Proteus mirabilis and Staphylococcus aureus demonstrated a zone of inhibition of $30 \mathrm{~mm}, 35 \mathrm{~mm}, 32$ $\mathrm{mm}$ and $29 \mathrm{~mm}$ respectively, whereas $100 \mathrm{mcg}, 200 \mathrm{mcg}$ and $300 \mathrm{mcg}$ doses of whole plant ethanolic extract of $S$. indicus demonstrated no zone of inhibition. 


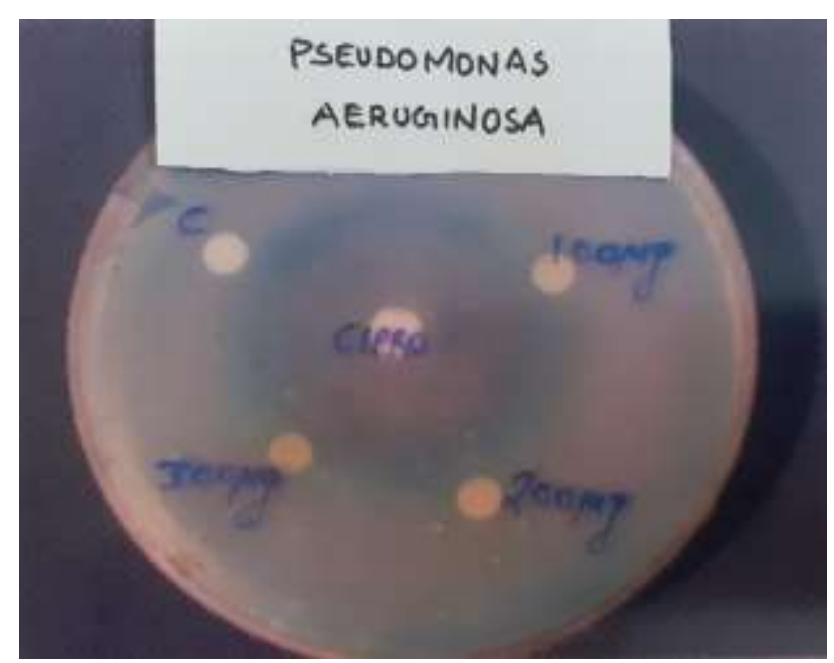

Figure 2: Effect of ethanolic extract of whole extract of S. indicus Linn, control and ciprofloxacin on growth of Pseudomonas aeruginosa.

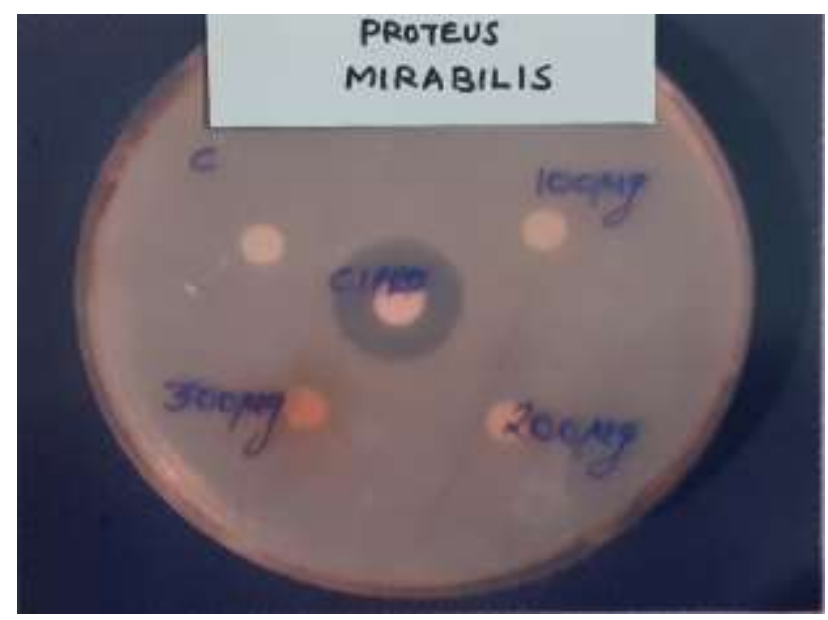

Figure 3: Effect of ethanolic extract of whole extract of S. indicus Linn, control and ciprofloxacin on growth of Proteus mirabilis.

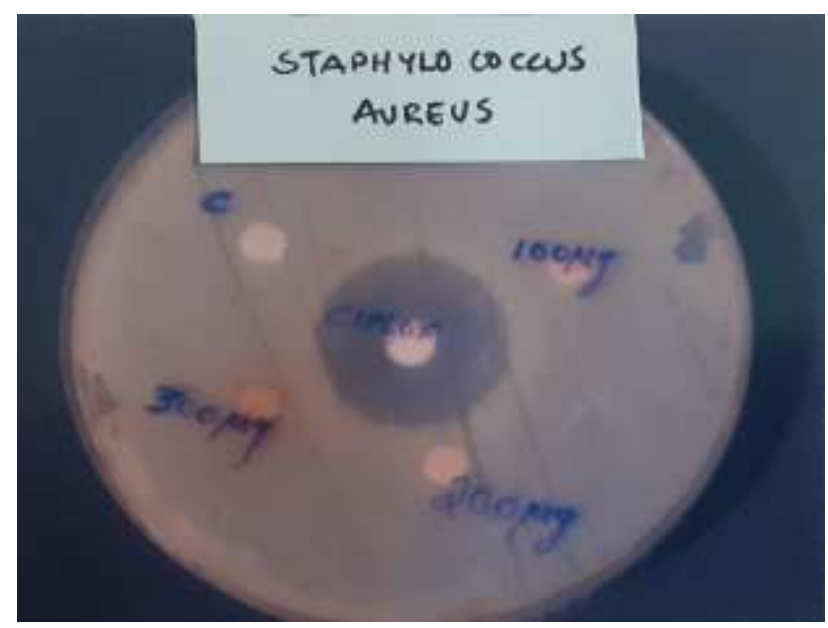

Figure 4: Effect of ethanolic extract of whole extract of S. indicus Linn, control and ciprofloxacin on growth of Staphylococcus aureus.
Table 1: Effect of $S$. indicus on the growth of bacteria in MHA plates compared with ciprofloxacin.

\begin{tabular}{|c|c|c|c|c|c|}
\hline \multirow{3}{*}{$\begin{array}{l}\text { Organ } \\
\text { ism }\end{array}$} & \multicolumn{5}{|c|}{ Zone of inhibition (mm) } \\
\hline & \multirow{2}{*}{$\begin{array}{l}\text { Standard } \\
\text { ciprofloxacin } \\
(30 \mathrm{mcg})\end{array}$} & \multirow[b]{2}{*}{$\begin{array}{l}\text { Control } \\
\text { DMF }\end{array}$} & \multicolumn{3}{|c|}{ Extract } \\
\hline & & & $\begin{array}{l}100 \\
\text { mcg }\end{array}$ & $\begin{array}{l}200 \\
\text { mcg }\end{array}$ & $\begin{array}{l}300 \\
\text { mcg }\end{array}$ \\
\hline E. coli & 30 & Nil & Nil & Nil & Nil \\
\hline $\begin{array}{l}\text { P. aerugi } \\
\text { nosa }\end{array}$ & 35 & Nil & Nil & Nil & Nil \\
\hline $\begin{array}{l}\text { P. mirabi } \\
\text { lis }\end{array}$ & 32 & Nil & Nil & Nil & Nil \\
\hline S. aureus & 29 & Nil & Nil & Nil & Nil \\
\hline
\end{tabular}

\section{DISCUSSION}

In recent times there has been considerable significance in the use of plant material as an unconventional method to control pathogenic microorganism, and many components of plants products have been shown to be particularly targeted against resistant pathogenic bacteria. ${ }^{7,8}$ Furthermore, the current price of most of the chemotherapeutic agents is on the rise hence steps should be taken to develop effective natural, non-toxic drug for treatment. ${ }^{9}$ Hence the present study was performed to explore the antimicrobial property of S.indicus. The whole plant ethanolic extract of $S$. indicus failed to demonstrate any antibacterial property against E. coli, Pseudomonas aeruginosa, Proteus mirabilis and Staphylococcus aureus in 3 doses (100 mcg, $200 \mathrm{mcg}$ and $300 \mathrm{mcg}$ when compared with ciprofloxacin $(30 \mathrm{mcg})$ as standard drug. This is in contrast to a study in which the antimicrobial activity of methanolic, ethanolic, chloroformic and aqueous extract of $S$. indicus $L$. were tested against the uropathogenic organisms E. coli, Klebsiella pneumoniae, P. mirabils, and Pseudomonas aeroginosa. It was found that out of the four extract the methanolic extract possessed higher degree of antibacterial activity against Escherichia coli. However, against Klebsiella pneumonia ethanolic extract of plant showed higher activity than any other extract, whereas against Proteus mirabils, chloroformic extract show similar inhibition zone as that with Kanamycin. It was also observed that against Pseudomonas methanolic and ethanolic extract shows similar activity, however it was higher than chloroform extract. $^{2}$

The aqueous and methanolic leaf extract of $S$. indicus have shown significant activity against S. faecalis. ${ }^{10}$ The hexane extract of $S$. indicus flowers possessed more antibacterial activity and antifungal activity than the aerial parts against gram positive organisms. ${ }^{1}$ Hexane extract of $S$. indicus (flowers and aerial parts) showed antimicrobial activity against most of the bacteria tested. Flower extract showed higher activity than the aerial parts against Gram positive bacteria such as $B$. subtilis, $S$. aureus, $S$. epidermidis and $E$. faecalis which were comparable with antibiotic Streptomycin (10 $\mu \mathrm{g} /$ disc $)$ Benzene, chloroform, ethyl acetate and acetone extracts of flower and aerial parts showed some activity at higher 
concentration ( $5 \mathrm{mg} / \mathrm{disc})$ against gram positive bacteria. ${ }^{1}$ Another in vitro study demonstrated that $S$. indicus essential oil showed maximum activity against the E. coli. Both gram positive and gram-negative bacteria were sensitive to this oil. ${ }^{11}$

Ethanol extract of $S$. indicus has antibacterial activity against enteropathogens. ${ }^{12}$ The fruits of $S$. indicus exhibited excellent antibacterial activity against gram positive as well as gram negative bacteria. ${ }^{13}$ It also possesses antifungal property. ${ }^{14}$ The $50 \%$ ethanolic extract of plant was reported to have hypoglycemic activity. ${ }^{15}$ Ethanolic extract of aerial part of $S$. indicus. was evaluated for wound healing activity in guinea pigs which enhanced the rate of wound contraction and the period of epithelialization and was comparable to neomycin. ${ }^{16}$ The plant was also found to exhibit anticancer activity and antiprotozoal activity against Entamoeba histolytica. ${ }^{15}$ Chloroform, methanol and aqueous extracts of $S$. indicus has shown high in vitro antibacterial activity against $S$. aureus, chloroform, methanol and ethanol extract against $P$. aeroginosa, methanol, chloroform and hexane against B. substilus, aqueous, methanol, ethyl acetate and chloroform against E. coli. ${ }^{17}$ In another study lowest MIC values were recorded in leaf extracts of $S$. indicus followed by stem and root extracts against Bacillus subtilis, Staphylococcus aureus, Escherichia coli, Pseudomonas, Klebsiella pneumonia. ${ }^{18}$ Similar antibacterial activity was observed in other plants of the same family. ${ }^{19}$

The ethanolic extract of $S$. indicus has demonstrated a dose dependent increase in urine volume in rat. The maximum diuretic and kaliuretic activity were observed at the dose of $300 \mathrm{mg} / \mathrm{kg}$ of the extract which confirms the basis for folklore use of $S$. indicus Linn as a diuretic agent. $^{20}$

Bioactive molecules in plants vary in potency hence efficacy of the extracts obtained also vary in their antibacterial activity. ${ }^{21}$ The chances of absence of antibacterial activity by the plant extracts were noted earlier also. An example is the reported resistance of E. coli against ethanolic extracts from neem leaves. ${ }^{22}$ Therefore, synergistic studies of plant extracts to identify a novel combination with much desired efficacy are needed. ${ }^{23}$

\section{CONCLUSION}

Previous literature observations had demonstrated antibacterial activity in various parts and extracts of $S$. indicus Linn. This study had demonstrated that the ethanolic whole plant extract of $S$. indicus lack antibacterial property. The reason can be attributed to environmental factors, regional differences that can affect the growth and chemical composition of plants. It can also be due to the method of extraction used. Further studies are needed to standardize the methods of extraction and also in vitro testing done to confirm the findings in this study. Meticulous attention to these issues should be considered for the emergence of a new era of antibacterial treatment that can be cost effective by using plant-derived principles.

\section{ACKNOWLEDGEMENTS}

I am deeply thankful and greatly indebted to Dr Dhanya S.P, Associate Professor, Department of Pharmacology, Government Medical college, Kottayam for assistance with synergy methodology, results interpretations and for comments that greatly contributed to the final manuscript.

\section{Funding: No funding sources \\ Conflict of interest: None declared \\ Ethical approval: The study was approved by the Institutional Ethics Committee}

\section{REFERENCES}

1. Duraipandiyan V, Kannan P. Ignacimuthu S. Antimicrobial activity of Sphaeranthus indicus 1 . Ethnobotanical Leaflets 2009;13:320-5.

2. Nadkarni KM. Indian Materia Medica, Popular Prakshan, Bombay, 1976;1:1126.

3. Chopra RN, Nayar SL, Chopra IC. Glossary of Indian medicinal plants. New Delhi: Council of Scientific \& Industrial Research. 1956.

4. Shakila Ramachandran. Review on Sphaeranthus indicus Linn. (Kotțaikkarantai) Pharmacogn Rev. 2013;7(14):157-69.

5. Singh SK, Saroj KM, Tripathi VJ, Singh AK, Singh RH. An Antimicrobial Principle from Sphaeranthus indicus L. (Family Compositae). Int J Crude Drug Res. 1988;26:235-9.

6. Shaikh D, Naqui BS, Shaikh R. The antimicrobial principles of Sphaeranthus indicus: Isolation, purification and antimicrobial action. Pak J Scientific Ind Res. 1986;29:366-71.

7. Nostro A, Cellini L, Bartolomeo SD. Effect s of combining extracts propolis or Zingiber officinale with clarithromycin on Helicobacter pylori. Phytothera Res. 2006;20(3):187-90.

8. Sarala GK, Shibumon G, Benny PJ. Antimicrobial effect of Punica grantum on pyogenic bacteria. J Pharma Biomed Sci. 2010;3(60:1-3.

9. Venkatachalam D, Thavamani SB, Muddukrishniah K. Antimicrobial activity of leaf of Sphaeranthus indicus against some selected human pathogenic bacteria J Med Pharmaceu All Sci. 2018;7(12):100816.

10. Irfan M, Ahmed S, Sharma M. Antimicrobial activity of terpenoids from Sphaeranthus indicus. L. Asia J Plan Sci Res. 2014;4(1):1-6.

11. Rachana GA, Pooja A, Pathak AK, Mukul T, Vaibhavi S. Screening of Chemical Composition and Antimicrobial Activity of Essential Oil Isolated From Flower Heads of Sphaeranthus Indicus Linn Against MRSA, ESBL, AMPC, and Carbapenamase 
Producing Bacteria. Int J Curr Pharmaceu Rev Res. 2015;6(3):153-63.

12. Vijaya K, Anathan S. Microbiological screening of Indian Medicinal plants with special reference to enteropathogens. J Altern Comp Med. 1997;3:13-20.

13. Naqvi BS, Hashmi K, Sheikh D, Mahdi A. Antibacterial activity in fruits and vegetables. Pak $\mathbf{J}$ Pharmacol. 1998;15:7-11.

14. Garg SC, Kasera HL. Antifungal activity of the essential oil of Sphaeranthus indicus Linn. Pafai J. 1982;4:23-4.

15. Dhar ML, Dhar MM, Dhawan BN, Mehrotra BN, Ray C. Screening of Indian plants for biological activity. Indian J Exp Biol. 1968;6:232-47.

16. Sadaf F, Saleem R, Ahmed M, Ahmad SI, Navaid-ulZafar Healing potential of cream containing extract of Sphaeranthus indicus on dermal wounds in guinea pigs. J Ethno pharmacol. 2006;107:161-3.

17. Zachariah SB, Pappachen LK, Aneesh TP, Alex L, Sumith G, John MS, et al. Phytochemical and Pharmacological screening of Sphaeranthus indicus Linn, for antimicrobial activity. Int J Pharm Sci Res. 2010;1(10):169-73.

18. Harathi K, Giribabu D, Naidu VC. Phytochemical Evaluation and in Vitro Antibacterial Activity of Sphaeranthus indicus (L.)- An Important Antijaundice Medicinal Plant. American J Plant Sci. 2017;08(05):1011-21.
19. Roos G, Prawat H, Walter CU, Klaiber I, Vogler B, Guse JH, et al. New sesquiterpene lactone with antibacterial activity from Vernonia fastigiata. Planta Medica. 1998;64:673.

20. Sundaresan PK, Prabhakaran SS, Palappallil DS, Chellappan D. Diuretic activity of ethanolic extract of whole plant of sphaeranthus indicus linn in albino rats. Int J Basic Clin Pharmacol. 2017;6:265-70.

21. Edward MG, Samuel NN, Stanley W, Gerald A. Synergistic antimicrobial activity of crude ethanolic extracts of garlic and neem leaves against bovine mastitis pathogens: an in vitro assay. Int $\mathbf{J}$ Basic Clin Pharmacol. 2017;6(9):2111-6

22. Goncagul G, Ayaz E. Antimicrobial effect of garlic (Allium sativum) and traditional medicine. J Ani Vet Advs. 2010;9(1):1-4.

23. Sivananthan M. Antibacterial activity of 50 medicinal plants used in folk medicine. Int Jour Biosci. 2013;3(4):104-21.

Cite this article as: Sundaresan PK, Kesavan KP. In vitro evaluation of antibacterial activity in ethanolic extract of whole plant Sphaeranthus indicus Linn. Int J Basic Clin Pharmacol 2020;9:1730-4. 